\title{
Aboveground biomass relationships for beech (Fagus moesiaca Cz.) trees in Vermio Mountain, Northern Greece, and generalised equations for Fagus sp.
}

\author{
Dimitris ZIANIS*, Maurizio MENCUCCINI \\ Institute of Ecology and Resource Management, Darwin Building, Mayfield Road, Edinburgh EH9 3JU, UK
}

(Received 5 July 2002; accepted 30 October 2002)

\begin{abstract}
Allometric equations describing tree size-shape relationships for beech (Fagus moesiaca Cz.) in the Vermio Mountains of Northern Greece are presented. Diameter at breast height explained most of the variability in the dependent variables (total aboveground, stem, and branch biomass), while tree height was the second most important regressor in estimating foliage mass. Equations developed in USA and Europe for Fagus spp. were also reported and validation with the field data indicated that the American regressions closely predicted total tree biomass for the study forest. In addition, the raw data were used to test a recent theoretical model and large deviations were found between theoretical and empirical values. Finally, generalised equations for Fagus spp. were developed based on these data and several other published equations. Validation of the generalised equations indicated that accurate predictions may be obtained when these regressions are applied over a broad geographical area.
\end{abstract}

allometry / biomass / generalised equations / Fagus moesiaca Cz. / Northern Greece

Résumé - Relations concernant la biomasse aérienne pour le hêtre (Fagus moesiaca Cz.), dans le massif du Vermio au nord de la Grèce, et équations génériques pour Fagus sp. Dans l'article suivant sont présentées des équations allométriques décrivant les relations taille-forme pour une espèce particulière de hêtre, Fagus moesiaca $(\mathrm{Cz}$.), dans le massif du Vermio, au nord de la Grèce. Le diamètre à hauteur de poitrine explique en grande partie la variabilité des variables indépendantes (biomasse aérienne totale, biomasse des tiges, biomasse des branches), tandis que la hauteur de l'arbre est la deuxième variable indépendante la plus importante lors de l'estimation de la masse du feuillage. Les équations développées aux États-Unis et en Europe pour les différentes espèces de hêtre (Fagus spp.) sont également présentées. Leur validation, obtenue avec les données recueillies sur le terrain, indique que les régressions américaines prédisent de manière précise la biomasse totale de l'arbre dans la forêt étudiée. En outre, les données de terrain ont été utilisées pour tester un modèle théorique récent, ce qui a permis de mettre en évidence de larges variations entre les valeurs théoriques et empiriques. Finalement, des équations génériques concernant $F a g u s$ spp. ont été développées à partir de ces données et de plusieurs autres équations publiées. La validation de ces équations génériques indique que des prédictions précises peuvent être obtenues quand les régressions sont appliquées à une large échelle géographique

allométrie / biomasse / équations génériques / Fagus moesiaca Cz. / nord de la Grèce

\section{INTRODUCTION}

Tree biomass plays a key role in sustainable management and in estimating the stocks of carbon (C) that forests contain. In addition to making estimates of $\mathrm{C}$ pools in forests, estimation of biomass is relevant for studying biogeochemical cycles, because the content of nutrient elements in forests is also related to the quantity of biomass present $[16,23,31]$. The most accurate way to determine values of wood biomass is to cut down the trees under investigation and perform appropriate measurements. However, destructively harvesting of forest biomass in sample plots is a time-consuming procedure and generates considerable uncertainty when the obtained results are extrapolated to larger areas [13]. Undoubtedly, the most common approach to obtain biomass estimates at stand level is through regression equations that are fitted to morphometric measurements taken from destructively sampling of individual trees. Subsequently, these regressions (also known as size allometry relationships) are used to estimate the biomass of sample plots within which the diameters and heights for all the

\footnotetext{
* Corresponding author: Zianis.Dimitris@ed.ac.uk
} 
Table I. Characteristics of the 4 stands sampled along an elevation gradient (as modified from Stefanidis [27]).

\begin{tabular}{lccccccc}
\hline Stand ID & $\begin{array}{c}\text { Elevation } \\
(\mathrm{m})\end{array}$ & Aspect (Slope) & $\begin{array}{c}\text { Density } \\
(\text { trees/ha) }\end{array}$ & $\begin{array}{c}\text { Basal area } \\
\left(\mathrm{m}^{2} / \mathrm{ha}\right)\end{array}$ & $\begin{array}{c}D \text { range } \\
(\mathrm{cm})\end{array}$ & $\begin{array}{c}\text { Mean height } \\
(\mathrm{m})\end{array}$ & $\begin{array}{c}\text { Mean annual } \\
\text { increment }\left(\mathrm{m}^{3} / \mathrm{ha}\right)\end{array}$ \\
\hline 20 & 1030 & N-NE $(20 \%)$ & 630 & 29.0 & $10-32$ & 23.0 & 5.98 \\
$16 \mathrm{~b}$ & 1310 & N-E (30\%) & 667 & 20.1 & $10-32$ & 14.0 & 4.17 \\
$12 \mathrm{a}$ & 1513 & N-W (31\%) & 744 & 19.3 & $10-36$ & 17.4 & 7.52 \\
$10 \mathrm{a}$ & 1820 & N-E (60\%) & 820 & 22.4 & $10-60$ & 13.9 & 2.68 \\
\hline
\end{tabular}

trees have been measured. Researchers throughout the globe have developed a plethora of allometric equations for different species growing in a wide range of environmental conditions. However, aboveground tree biomass values vary with species, stand age, site quality, climate, and stocking density of stands $[1,4,11]$. Implementing allometric equations beyond the specific site and the diameter range for which they were developed is anticipated with scepticism. To circumvent this problem, Pastor et al. [21] developed generalised allometric equations for several north-American species and tests against field data indicated quite accurate predictions for some of them. Ketterings et al. [9] supported that aboveground biomass could be estimated without destructive measurements on sampled trees. They suggested that the parameters of allometric equations in biomass studies should depend on the average wood density, and on the exponent of the tree height-diameter relationship (see [9] for the detailed approach).

In a theoretical context, the allometric equations describing tree size-shape relationships are believed to be affected by the physiological requirements to conserve water and to support large loadings against the influence of gravity and/or wind forces [17]. With reference to foliage biomass, the underlying principle supports the idea that a unit of evaporating leaves is sustained by a unit of vascular pipes. This approach was developed by Shinozaki et al. [25] and is known as the "pipe model theory". Originally, it was thought that leaf mass was directly proportional to the basal area of the stems and branches, but several studies empirically demonstrated that the amount of foliage mass was strongly correlated with sapwood area e.g. [14]. McMahon and Kronauer [12] studied the scaling of tree height with respect to stem diameter using the stress and the elastic similarity models. Assuming a constant stem density, predictions about the relation between trunk mass and diameter are readily obtained [17]. Recently, West et al. [30] integrated the biomechanical and hydraulical principles of tree architecture, and developed a model which seems to predict quite accurately several structural plant variables (tree height and diameter, number of leaves, number of branches, etc.) in relation to plant body size (i.e. plant biomass). They supported that theoretical values obtained by the model are accurate enough to predict aboveground forest biomass. Parde [19] reviewed historical and methodological aspects of forest biomass studies and Cannell [4] compiled data on biomass production from studies conducted throughout the world.

The objective of this study is to develop biomass equations for beech (Fagus moesiaca Cz.) trees growing in Vermio Mountain, Northern Greece. Some preliminary results were presented by Zianis and Mencuccini [35]; in this paper, a more detailed analysis is attempted. The obtained equations are compared with the allometric equations for beech trees found in the literature and with theoretical model presented by West et al. [30]. Finally, an approach similar to that of Pastor et al. [21] was used in order to build and validate generalised allometric equations for Fagus genus. The obtained allometric relationships will be used to investigate the primary productivity of beech stands along an elevation gradient.

\section{MATERIALS AND METHODS}

\subsection{Study area}

The Vermio Mountain is situated in the central part of Northern Greece, about $80 \mathrm{~km}$ West of Thessaloniki, with a North-South orientation. The East-facing slopes are influenced by pluvial aerial masses originating from the Aegean Sea resulting in highly productive ecosystems in comparison to West-facing sites. The study forest $\left(40^{\circ} 32^{\prime} \mathrm{N}, 21^{\circ} 58^{\prime} \mathrm{E}\right)$ is located on the Eastern slopes of Vermio Mountain, spanning from 380 to $2052 \mathrm{~m}$ above sea level and belongs to the Municipality of Naousa town. Several plant species (Pinus nigra Arn., Abies borissi-regis Mattf., Castanea sativa Miller., Ilex aquifolium L., Juniperus sp., Quercus sp., Salix sp., Populus sp., Platanus sp, Acer sp., Fraxinus sp., Buxus sempervirens L., Cornus sp., Prunus sp., Robus sp., etc.) could be found in this ecosystem. The climate of the forest can be classified as temperate Mediterranean with rainy winters and warm summers and the total annual rainfall is $1500 \mathrm{~mm}$ [27]. Minimum rainfall occurs during the July-August period, but the atmosphere is not totally dry due to the vicinity to archipelagos.

The Balkan region and particularly Northern Greece, is the contact zone of the European Beech ( $F$. sylvatica subsp. sylvatica L.) and Oriental beech ( $F$. sylvatica subsp. orientalis Lipsky). Strid and Tan [28] supported that $F$. sylvatica subsp. sylvatica and $F$. sylvatica subsp. orientalis are typical geographical races of $F$. sylvatica and several individuals have been recorded to be more or less intermediate between these subspecies. Such hybrids are referred to as $F$. sylvatica subsp. moesiaca $\mathrm{Cz}$. (Moesian beech) with leaves characterised by 5-9 pairs of lateral veins and seeds often presenting somewhat spathulate basal cupule scales. However, Moesian beech is reported to be the prevalent species in Central and North-west Greece $[6,8,24]$ and the morphological characteristics of the study trees resemble the Moesian type rather than the European form. Naturally regenerated, pure beech (Fagus moesiaca Cz.) stands occupy a total area of $2121 \mathrm{ha}$, stretching from $900 \mathrm{~m}$ to $1900 \mathrm{~m}$ and covering a range of various topographical conditions (see Tab. I). Due to the disturbed history of the forest (clearcut fellings during the 19th century and several fire events during World War Two), it is usual to meet cohorts within stands that belong to different age- and consequently size-classes.

\subsection{Tree level data}

Sixteen trees were harvested from the stands described in Table I for the parameterisation of the allometric equations and the diameter 
(D) range of the felled trees spanned from 5.19 to $40.6 \mathrm{~cm}$ so as to represent the diameter distribution reported in the forest management plan.

The following variables related to tree dimensions were recorded per sample tree: the diameter at $0.30 \mathrm{~m}$ above ground $\left(D_{B}\right)$, the diameter at $1.30 \mathrm{~m}(D)$, the diameter at the base of the live crown $\left(D_{C}\right)$, the total height $(H)$, the height to the base of the live crown $\left(H_{S}\right)$, diameters $\left(D_{B R}\right)$, lengths $\left(L_{B R}\right)$ and positions of the branches on the stem. The tree bole was cut at $0.30 \mathrm{~m}$ and at $1 \mathrm{~m}$ intervals thereafter up to the base of the live crown (i.e. the point where the main stem bifurcated), and the part of the stem within the crown was separated from branches. After felling the tree, the stump was also removed. The leaves of each branch were collected and put into plastic bags. The stem sections (including bark), the stump, the branches and the leaves were transported to the laboratory and oven dried to constant weight at $80^{\circ} \mathrm{C}$. Before felling, the horizontal projections of the 8 longest branches (excluding epicormics) were pointed down and the horizontal crown projection area $(\mathrm{Pa})$ was determined assuming that it could be compared to a circle or to an ellipse.

\subsection{Regression analysis}

Foresters and ecologists have used different models for estimating forest biomass. Undoubtedly, the most commonly used mathematical model is the allometric equation corresponding to the following power form:

$$
Y=a X^{b}
$$

where $a$ and $b$ are the scaling coefficients that vary with the variables under investigation; $Y$ is the total biomass or one of its components and $X$ a tree dimension variable (i.e. $D, D^{2}, D^{2} H, D H$, etc.).

Payandeh [22] further classified model (Eq. (1)) into two types: the "intrinsically linear" type which assumes a multiplicative error in raw data and the "intrinsically nonlinear" type with an additive random error. In the "intrinsically linear" model, the original data are log-transformed and the least square method is applied in order to estimate the parameters. In many cases, log-transformation of raw data results in homoscedasticity of the dependent variable $Y$, a prerequisite for the regression methods. However, even though the logarithmic equation is mathematically equivalent to equation (1), they are not identical in a statistical sense [34]. Using the logarithmic form of equation (1), produces a systematic underestimation of the dependent variable $Y$ when converting the estimated $\ln Y$ back to the original untransformed scale $Y$. Although this inherent bias has long been recognised [7], concern of its potential impact on estimates of biomass is relatively recent $[10,15,26]$. Several procedures for correcting bias in logarithmic regression estimates have been advocated $[2,3,26$, 33].

Let $\hat{Y}_{c}=e^{1 \hat{n} a+\hat{b} \ln X}$ be the mean predicted value for a given $X$ in arithmetic units. According to [2], an approximation of the corrected, unbiased estimate is

$$
\hat{Y}_{c}=e^{1 \hat{n} a+\hat{b} \ln X+C F}
$$

where $C F=S E E^{2} / 2$ is the correction factor and $S E E=$ $\sqrt{\sum\left(\ln Y_{i}-\ln Y_{i}\right)^{2} /(n-p)}$ is the standard error of the estimate of the regression; $n$ and $p$ denote the number of the observations and the fitted parameters, respectively.

Madgwick and Satoo [11] found from intensive simulated sampling of actual weights that with some corrections, values tend to be overestimated, and they suggested that, as the bias from re-transformation is generally small compared to the overall variation in the estimate of biomass, the correction factor be ignored. In addition, Beauchamp and Olson [3] reported that data on stem biomass of Liriodendron tulipifera $\mathrm{L}$. showed small bias $(<1 \%)$ in the predicted dry weight obtained from the biased (uncorrected) estimate. For the purposes of the present study, $a$ and $b$ values are reported for the biased regression in conjunction with the correction factor $C F$ as given by Sprugel [26].

Yandle and Wiant [33] reported that the bias $B=\hat{Y}_{c}-\hat{Y}$, as a percent of the unbiased estimate equals to

$$
\text { Percent bias }=\left(\left(e^{C F}-1\right) / e^{C F}\right) 100
$$

and is constant over the range of $X$ values. Wiant and Harner [32] suggested that it is informative to express the standard error of $\hat{Y}_{c}$ for a given $X$ as a percent of $\hat{Y}_{c}$. This becomes

$$
\text { Percent standard error }=\left(e^{C F}-1\right)^{1 / 2} 100
$$

which is also constant over the range $X$ values.

Usually, the validity of the relationship is tested by the coefficient of determination of the logarithmic regression, $R^{2}$, and SEE is computed for the entire dataset of the transformed data. However, high values of $R^{2}$ and small values of SEE (typically obtained in allometric studies) do not guarantee precision of the estimate, when values are back transformed to the linear scale. Thus, it is not unusual that, for a specific diameter, the predicted biomass $\hat{Y}$ deviates by a relative amount of $90 \%$ from the corresponding observed value.

On the other hand, the general linear regression procedure does not apply to the "intrinsically nonlinear" model and iterative procedures are required for estimating the allometric parameters. Payandeh [22] reviewed and compared the log-transformed linear model with the simple nonlinear form and pointed out that the latter model resulted in better fit for two datasets of Betula alleghaniensis Britton and Acer saccharum Marsh.

Another basic point about allometric studies is that researchers rarely validate the obtained relationships with data other than the ones that were used in regression analysis. Madgwick [10] pointed out that if models are to be used for prediction purposes, they should be evaluated with new data. Moreover, it must be emphasised that allometric relationships are only valid over a certain $X$ interval of the independent variables, and extrapolation to either higher or lower values may result in large deviations between real and predicted values.

Parresol [20] reported several statistics for evaluating goodnessof-fit and for comparing alternative biomass models. The mean percentage difference $(M P D)$ between the predictions and the raw data was used to assess the performance of different models. This statistic gives the average deviation of the regression, relative to the raw data, and assesses the variability of the fitted equation. $M P D$ is calculated as the average of differences between observed and predicted values divided by the observed $[17,22]$.

\subsection{Generalised equations}

Apart from estimating biomass values at stand level, predictions at landscape scale are also needed, especially for $\mathrm{C}$ related studies. Since it would be unrealistic to develop allometric equations for each stand found in a region, Pastor et al. [21] built generalised equations based on published allometric relationships. Quite a similar approach is presented in this paper in order to obtain generalised equations for beech trees, which were derived from American and Europeans studies (Tab. II).

The $D$ range of each dataset was divided into four classes and the mean value of each class was used to derive the total aboveground biomass $\left(M_{T}\right)$ predictions from the original equations. These $M_{T}-D$ pairs (28 in total) were log-transformed and a generalised equation for aboveground dry biomass of beech trees was subsequently obtained. 
Table II. Published equations for beech trees of the form $\mathrm{Y}=a \mathrm{X}^{b}$ used to develop generalised allometric relationships for aboveground dry biomass.

\begin{tabular}{lccccccc}
\hline \multicolumn{1}{c}{ Species } & $a$ & $b$ & $R^{2}$ & $D(\mathrm{~cm})$ & $\mathrm{N}^{*}$ & Region & Source \\
\hline Fagus grandifolia & 0.2013 & 2.2988 & n/a & $3-66$ & 29 & USA, Maine & [29] \\
Fagus grandifolia & 0.1958 & 2.2538 & 0.99 & $2-29$ & 46 & USA, New Brunswick & [29] \\
Fagus grandifolia & 0.1957 & 2.3916 & 0.99 & $1-60$ & 14 & USA, New Hampshire & [29] \\
Fagus grandifolia & 0.0842 & 2.5715 & 0.97 & $5-50$ & 56 & USA, West Virginia & [29] \\
Fagus sylvatica L. & 0.0798 & 2.601 & 0.99 & $2-32$ & 32 & EU, Netherlands Centre & {$[1]$} \\
Fagus sylvatica L. & 0.1326 & 2.4323 & 0.99 & $4-35$ & 7 & EU, Spain North & [23] \\
Fagus moesiaca Cz. & 0.2511 & 2.3485 & 0.99 & $5-41$ & 16 & EU, Greece North & This study \\
\hline
\end{tabular}

* Number of harvested trees.

Table III. Regression equations of the form $Y=\ln a+b X$. The standard errors of the estimates (s.e.) are significant at the 5\%-level. $R^{2}, S E E$, $C F$, and SSE denote respectively the coefficient of determination, the standard error of the estimate for 14 degrees of freedom, the correction factor and the sum of squares for error in arithmetic units. Percent bias and Percent s.e. were computed with equation (2) and equation (3) respectively. The number of sampled trees was 16 .

\begin{tabular}{cccccccccccccc}
\hline$Y$ & $X$ & $\ln a$ & $b$ & $R^{2}$ & s.e. $(a)$ & s.e. $(b)$ & $S E E$ & $C F$ & Percent bias & Percent s.e. & $S S E$ & $M P D(\%)$ \\
\hline $\ln M_{T}$ & $\ln D$ & -1.3816 & 2.3485 & 0.99 & 0.2080 & 0.0724 & 0.1841 & 1.0171 & 1.6819 & 18.5762 & 139617.36 & 14 \\
$\ln M_{S}$ & $\ln D$ & -1.6015 & 2.3427 & 0.98 & 0.2358 & 0.0821 & 0.2088 & 1.0220 & 2.1563 & 21.1099 & 91511.54 & 16.06 \\
$\ln M_{B T}$ & $\ln D$ & -5.2898 & 2.9353 & 0.97 & 0.3686 & 0.1284 & 0.3264 & 1.0547 & 5.1902 & 33.5387 & 14925.35 & 25.38 \\
$\ln M_{B C}$ & $\ln D$ & -6.3807 & 3.1037 & 0.95 & 0.5573 & 0.1941 & 0.4936 & 1.1295 & 11.4707 & 52.5287 & 13605.48 & 37.82 \\
$\ln M_{B E}$ & $\ln D$ & -5.9523 & 2.7501 & 0.75 & 1.2032 & 0.4191 & 1.0657 & 1.7645 & 43.3271 & 145.379 & 12658.01 & 86.89 \\
$\ln M_{F T}$ & $\ln D$ & -4.1814 & 1.6645 & 0.90 & 0.4362 & 0.1519 & 0.3863 & 1.0774 & 7.19 & 40.1176 & 10.94 & 39.92 \\
$\ln M_{F C}$ & $\ln D$ & -5.5168 & 1.9979 & 0.87 & 0.5970 & 0.2079 & 0.5287 & 1.15 & 13.0474 & 56.7997 & 8.67 & 40.26 \\
$\ln M_{F E}$ & $\ln D$ & -3.5789 & 0.9021 & 0.40 & 0.8420 & 0.2933 & 0.7458 & 1.3206 & 24.2792 & 86.2607 & 3.25 & 59.36 \\
$\ln M_{S P}$ & $\ln D$ & -1.7716 & 1.0730 & 0.78 & 0.4398 & 0.1532 & 0.3895 & 1.0788 & 7.3068 & 40.4809 & 35.3 & 27.86 \\
$\ln M_{C S}$ & $\ln D$ & -4.0543 & 2.2116 & 0.87 & 0.6683 & 0.2328 & 0.5918 & 1.1914 & 16.068 & 64.7719 & 1328.3 & 44.47 \\
$\ln M_{C W}$ & $\ln D$ & -4.1293 & 2.6741 & 0.96 & 0.4038 & 0.1407 & 0.3576 & 1.0660 & 6.1942 & 36.9358 & 12433.56 & 34.6 \\
$\ln H$ & $\ln D$ & 1.4192 & 0.5358 & 0.89 & 0.1459 & 0.0508 & 0.1292 & 1.0083 & 0.8315 & 12.9768 & 112.13 & 9.5 \\
$\ln H_{S}$ & $\ln D$ & 1.2238 & 0.4677 & 0.75 & 0.2052 & 0.0715 & 0.1818 & 1.0166 & 1.639 & 18.33 & 86.75 & 14.12 \\
$\ln D c$ & $\mathrm{D}$ & 1.1544 & 0.0504 & 0.91 & 0.0949 & 0.0042 & 0.1869 & 1.0176 & 1.7328 & 18.862 & 121.69 & 14.37 \\
\hline
\end{tabular}

$M_{T}$ : total aboveground biomass, $M_{S}$ : stem mass, $M_{B T}$ : branch mass (including epicormics), $M_{B C}$ : branch mass in crown, $M_{B E}$ : mass of epicormic branches, $M_{F C}$ : foliage mass in crown, $M_{F E}$ : foliage mass of epicormics branches, $M_{F T}=M_{F C}+M_{F E}, M_{S P}$ : stump mass, $M_{C S}$ : the mass of the stem within the crown, $M_{C W}=M_{B C}+M_{C S}$. For $D, D c$, and $H$ see Section 2.2. Biomass is expressed in $\mathrm{kg}$, diameter in $\mathrm{cm}$, and height in $\mathrm{m}$.

\section{RESULTS}

\subsection{Allometric equations}

Scatter plots of the data indicated that biomass values for different tree compartments, as well as for $\mathrm{H}, \mathrm{H}_{\mathrm{S}}, \mathrm{D}_{\mathrm{C}}$ and $\mathrm{Pa}$, were non-linearly related to $D$. Subsequently, the raw values were transformed using the Napierian logarithmic function and the least squares method was applied to estimate the parameters of the models. The results are presented in Table III and surprisingly strong relationships were obtained in almost all cases.

In one case however, the mass of the leaves of the epicormics branches $\left(M_{F E}\right)$ was not highly correlated to $D$ as indicated by the $R^{2}$ of the log-transformed data. The $M P D$ for $M_{B E}$ was about $87 \%$ but $D$ explained $75 \%$ of the variability of the biomass of epicormic branches. Stronger relationships are reported for total foliage biomass $\left(M_{F T}\right)$ and for the mass of leaves found in the canopy $\left(M_{F C}\right)$. In the following equations, $H$ is introduced as the second independent variable and slightly better predictions for $M_{F T}$ and $M_{F C}$ were obtained than with the allometric equation including only $D$ :

$M_{F T}=0.0001997(0.000012) D^{2} H+0.331(0.227), R^{2}=0.9493$

and

$M_{F C}=0.0001663(0.000013) D^{2} H+0.224(0.243), R^{2}=0.919$.

The standard errors of the estimates are presented in the parentheses; in both equations the slopes were statistically different from zero but the $95 \%$ range of the intercepts included this value.

However, the addition of $H$ for predicting the biomass of other tree compartments did not substantially contribute to the 


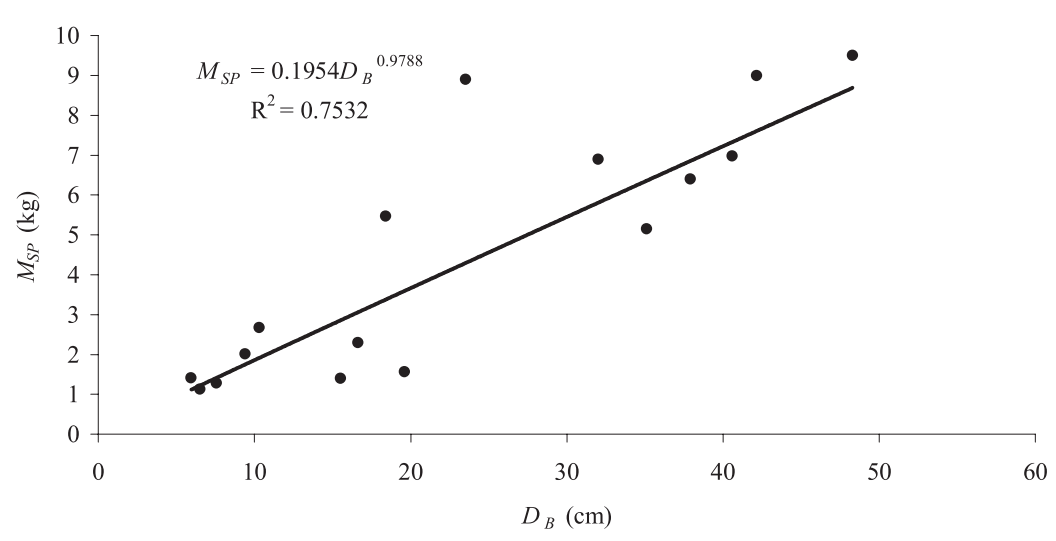

Figure 1. Stump biomass $M_{S P}$ in relation to $D_{B}$. The slope is statistically different from one.

Table IV. Regression equations of the form $Y=a X^{b}$. Symbols as in Table III.

\begin{tabular}{llccccccc}
\hline$Y$ & $X$ & $a$ & $b$ & $R^{2}$ & s.e. $(a)$ & s.e. $(b)$ & $S S E$ & MPD $(\%)$ \\
\hline$M_{T}$ & $D$ & 0.9402 & 1.9643 & 0.97 & 0.4897 & 0.1474 & 87058.6 & 25.77 \\
$M_{S}$ & $D$ & 0.7568 & 1.9536 & 0.97 & 0.4007 & 0.1498 & 54623.8 & 25.88 \\
$M_{B T}$ & $D$ & 0.1097 & 2.0545 & 0.91 & 0.116 & 0.2985 & 8467.7 & 45.43 \\
$M_{F T}$ & $D$ & 0.0057 & 1.9836 & 0.96 & 0.0035 & 0.1758 & 5.23 & 39.92 \\
\hline
\end{tabular}

increase of $R^{2}$ or to the decrease of $S E E$. The height of the stem was also closely related to $D$ according to $H_{S}=3.4001 D^{0.4677}$ (as transformed from the logarithmic equation in Tab. III).

Stump mass generally increased with increasing $D$ (Tab. III) or $D_{B}$ (Fig. 1) but a large variability occurred, which resulted in a rather low $R^{2}$.

Subsequently, the stump shape was approximated as a cylinder with diameter and height equal to $D_{B}$ and $0.3 \mathrm{~m}$ respectively, and the standard volume formula was used for predicting $M_{S P}$; however, this approach did not significantly decreased the SEE (data not shown).

A highly exponential relationship between $\ln D_{C}$ and $D$ was obtained (Tab. III) which, after transformation of the coefficients to arithmetic scale reads as

$$
D c=3.172 e^{0.0504 D}
$$

where $e$ is the base of Napierian logarithms. The horizontal projection area of crown $(\mathrm{Pa})$, was also non-linearly related to $D$ and the empirical relationship was

$$
P a=1.2830(0.1121) \ln D-0.9004(0.321)
$$

with $R^{2}=0.9034$, and standard errors in parentheses.

The percent bias was computed according to equation (2) and resulted in a rather low estimate of $3.98 \%$. Thus, no procedures were adopted in order to eliminate the inherent bias and the antilog of the logarithmic predicted values were used to derive the power function

$$
P a=0.4064 D^{1.2830}
$$

with sum of squared errors, $S S E=1021.99$ (in linear scale); the projection area was measured in $\mathrm{m}^{2}$ and $D$ in $\mathrm{cm}$.

Larger values of percent bias $(43.43 \%)$ were obtained for the equation that relates the biomass of epicormics branches
$\left(M_{B E}\right)$ to $D$; however, the $S S E$ of the biased and corrected equations was 12.658 and 12.657 respectively (in linear scale), indicating that unbiased predictions do not significantly reduce the residual error.

Finally, the pooled data for the branches were used to derive the following relationship between branch biomass $M_{B R}$ and branch diameter $D_{B R}$ :

$$
\ln M_{B R}=3.415(0.062)+2.818(0.056) \ln D_{B R}
$$

with $R^{2}=0.889, S E E=0.6871$, and standard errors of parameters in parentheses.

The equations developed so far were assumed to comply with the "intrinsically linear" model and the least squares method was applied to log-transformed data in order to derive empirical values for the parameters of the allometric relationships. However, if one assumes an additive error term in the original data, then predictions should be based on nonlinear functions. The underlying model requires iterative procedures [22] for parameter estimation. Nonlinear equations were developed for the major tree biomass compartments (Tab. IV).

\subsection{Generalised equations}

A generalised equation for the aboveground biomass was developed, based on published allometric equations (see Tab. II) and the obtained relationship in logarithmic form is following:

$$
\ln M_{T}=2.45(0.055) \ln D-2.004(0.168)
$$

with $R^{2}=0.987, S E E=0.1876$, standard errors in parentheses; (see Fig. 2).

Raw data for $M_{T}-D$ pairs reported by Santa Regina and Tarazona [23] were used, in conjunction with the new dataset reported in this study, to validate the generalised equation. To avoid confounding results, the Spanish and Greek equations 

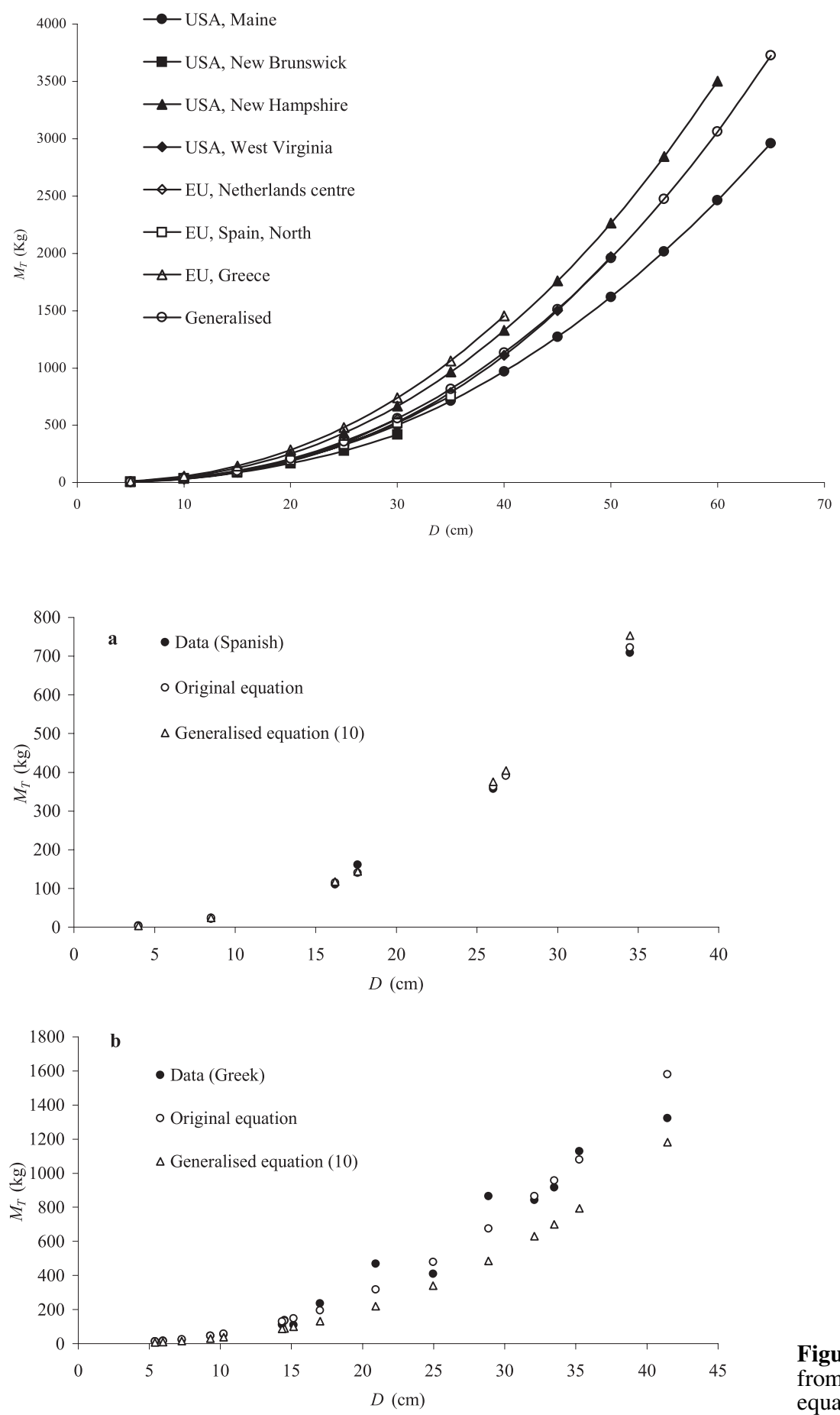

Figure 2. Generalised equation (9) and original equations for aboveground biomass $M_{T}$ ).
Figure 3. Predicted values for aboveground biomass $\left(M_{T}\right)$ from the generalised equation (10) and from original equations for the (a) Spanish and (b) Greek datasets. were excluded for the development of the new generalised equation which takes the form:

$$
\ln M_{T}=2.456(0.05) \ln D-2.073(0.156)
$$

with $R^{2}=0.992, S E E=0.1551$, (standard errors in parentheses).

The new generalised equation (10) very closely predicted biomass values for the Spanish dataset and there was virtually no difference between estimations made by the original and by the generalised regression (Fig. 3a). On contrary, the generalised equation did not accurately fit the data collected from the Greek stand (Fig. 3b).

For the original equation $M P D=13.54 \%$, while the generalised regression yielded a $M P D$ of $31.17 \%$. In addition, the pooled data from the two datasets were used to validate the 

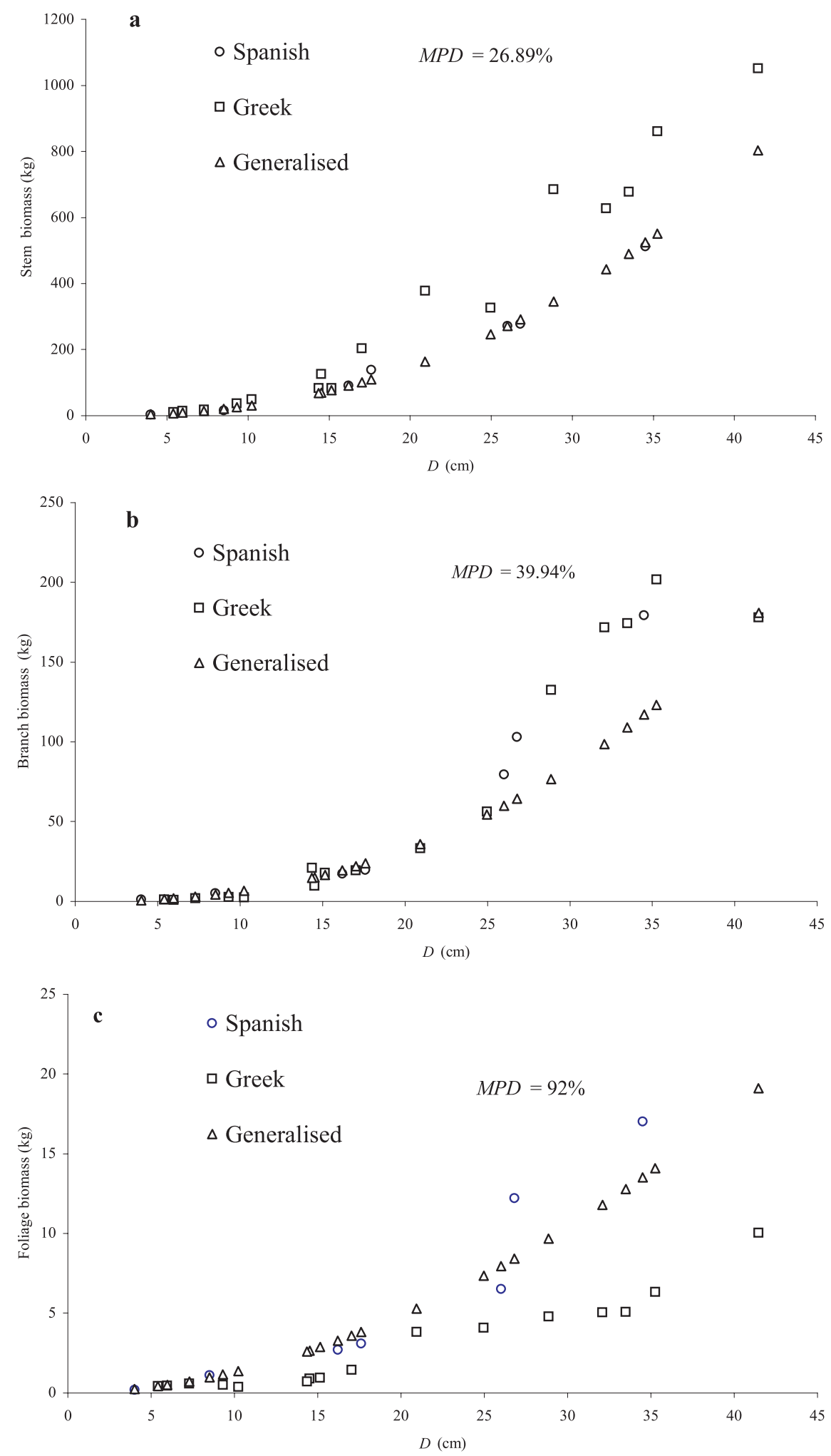

Figure 4. Generalised equations for (a) stem (b) branches and (c) foliage biomass together with the pooled datasets from the Spanish and Greek stand. The Spanish and Greek original equations were excluded from the development of the generalised function. The $M P D$ value refers to the pooled data. generalised relationship. A $M P D$ of $23.82 \%$, which denotes a rather accurate estimate, considering that no adjustments were introduced to take into account the different anatomical and morphological characteristics of the harvested trees (stand structure, wood density, tree age, tree height, etc.). Generalised equations for other tree compartments (stem, branches, foliage) were also developed for Fagus spp. and the results are presented in Figure 4 (see also Tab. V). 


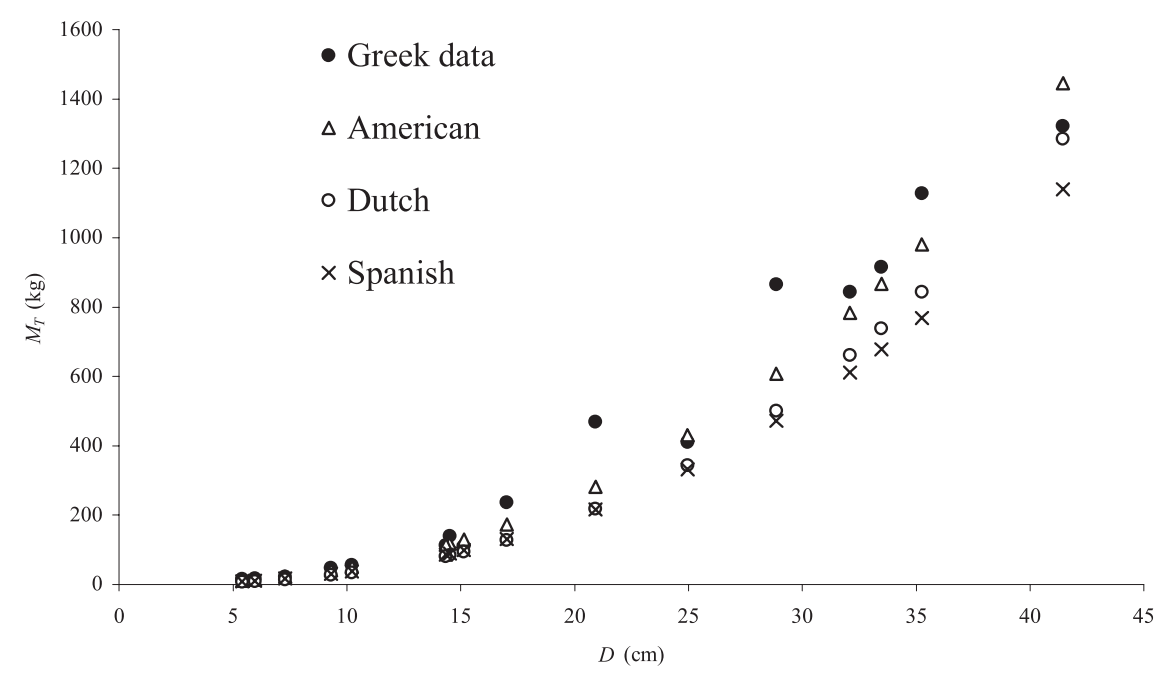

Figure 5. Comparisons between published equations for aboveground biomass $\left(M_{T}\right)$ and field data collected from the studied forest in Greece.

Table V. Generalised equations for different tree compartments for Fagus spp. derived from the sources presented in Table II. MPD denotes the average deviation of the generalised predictions in relation to the original equations.

\begin{tabular}{|c|c|c|c|c|c|}
\hline Compartment & $a$ & $b$ & $D$ range $(\mathrm{cm})$ & $R^{2}$ & $M P D$ \\
\hline Total & 0.1348 & 2.4500 & $1-66$ & 0.99 & $14.86 \%$ \\
\hline Stem & 0.1321 & 2.3594 & $1-66$ & 0.99 & $12.67 \%$ \\
\hline Branches & 0.0219 & 2.4208 & $1-66$ & 0.77 & $58.11 \%$ \\
\hline Foliage & 0.0188 & 1.8169 & $1-66$ & 0.86 & $32.29 \%$ \\
\hline
\end{tabular}

To assess the variability of the generalised equations relatively to the original regressions, Pastor et al. [21] reported three statistics. In this paper, the $M P D$ between the predictions made by the generalised and the original equations was calculated for different biomass components and presented in Table V.

\subsection{Comparison between equations}

The American regression (developed in New Hampshire) better predicted the Greek raw $M_{T}$ values (Fig. 5), than the Spanish and Dutch equations which deviated by a large amount in relation to the raw data, constantly underestimating the aboveground dry biomass values.

This trend was also evident for the stem and foliage biomass, but the most accurate prediction for branch mass was obtained with the Dutch regression. In addition, it is illustrated in Figure 5 that the equation developed from beech trees harvested in Netherlands accurately predicted $M_{T}$ from the Spanish dataset.

We also explored the applicability of a new theoretical model at the stand and regional scale, by comparing the predictions against the Spanish and the Greek datasets. According to West et al. [30], the theoretical exponent $(b)$ in the power function (Eq. (1)) equals 2.67 for the aboveground biomass, independently of species or site under investigation, but no estimation is given for the parameter $a$. However, Chambers et al. [5] reported that $a$ is $c a$. 0.1002, and this value was used to derive theoretical predictions. The MPD between the theoretical and raw values for the Greek dataset was $23.65 \%$ with the highest value amounted to $58 \%$ for the largest tree $(D=$ $41.45 \mathrm{~cm})$ and to $40 \%$ for the smallest tree $(D=5.39 \mathrm{~cm})$. The $M P D$ was larger for the Spanish data $(49 \%)$ and the highest value was equal to $80 \%$ for a tree with a diameter equal to $34.5 \mathrm{~cm}$.

\section{DISCUSSION}

\subsection{Allometric relationships}

Diameter at breast height explained much of the variability in biomass values of different tree compartments. Adding $H$ as a second variable, improved predictions for foliage biomass were obtained, in accordance with Bartelink [1]. However, tree height did not substantially decrease the $S S E$ for the regressions of total, stem, and branch biomass. The high correlation between $D$ and $H$ may explain the low gains in predictions when the latter variable is included in allometric models (multicolinearity). Mcmahon and Kronauer [12] examined the scaling of tree height based on stress and elastic similarity models and Niklas [17] reported that, for very old dicot trees, $H \propto D^{0.474}$ implying that mature trees taper so as to maintain a constant elasticity throughout the tree. In this study, the $95 \%$ confidence intervals for the reduce major axis scaling exponent of $H$ against $D$ are $0.45-0.66$ and indicate that wind-pressure dynamic loadings most likely affect the size-shape relationship of the study trees. Strong scaling relationships were also found between different tree dimensions (i.e. $\mathrm{Pa}, \mathrm{Dc}, \mathrm{H}_{S}$ ) and $D$ as well as between branch biomass and branch diameter. It 
is obvious that stump biomass is not so tightly related to either $D$ or $D_{B}$ as indicated by the $R^{2}$ values (Tab. III and Fig. 1). An explanation could be that the sample trees were located at sites with different slopes, which in turn may influence the shape butteressness - of the lowest part of the stem. This variability in shape could not be captured by $D_{B}$ alone and it is speculated that other variables might be more useful in predicting stump biomass. However, the information collected from the harvested trees could not be used to thoroughly test this hypothesis; compared to total tree biomass, stump mass is a very small proportion and any deviations from real values would be insignificant when extrapolated to stand scale. In statistical terms, the highest inherent bias recorded in the dependent variables after log-transformation was for the biomass of epicormic branches: the percentage bias value was equal to $43.32 \%$ (Tab. III). Applying the appropriate formula to eliminate this bias, the $S S E$ was insignificantly reduced (from 12658.01 to 12657.9); this observation was also true for other tree compartments, in accordance with [3] and [11]. When nonlinear models (Tab. IV) were compared with log-transformed regressions (Tab. III) it appeared that the former fitted the field data better than the latter as implied by the SSE. However, in terms of $M P D$, the linear models appeared to deviate less than the simple power functions, for total aboveground, stem and branch biomass.

Since data were pooled from stands with different structural and topographical characteristics (Tab. I), one could expect that quite accurate estimates may be obtained if the presented equations are to be applied throughout the study forest. Thus, the established relationships may be quite useful for the sustainable management of the investigated forest since no model existed so far for biomass estimations and the planning activity was totally based on the experience of foresters rather than on statistically sound methods.

\subsection{Generalised equations}

Aboveground biomass was estimated very accurately by generalised equations in the case of Spanish stand (Fig. 3a). On the other hand, the mean percentage difference $(31.17 \%)$ between the generalised equation and the Greek dataset was relatively high (Fig. 3b), but within the range (10-35\%) reported for published regressions developed from field data (Pastor et al. [21]). Mean variability between predicted and pooled stem biomass data was less than $27 \%$ (Fig. 4a), and was about $40 \%$ for the pooled branch biomass data (Fig. 4b). Generalised regression for foliage mass failed to predict the Greek data correctly $(M P D=123 \%)$ but reasonably approximated the values of the Spanish stand $(M P D=20 \%)$. The large deviation for the Greek dataset may be explained by the fact that foliage mass is strongly related to sapwood area rather than to $D$, as documented in several studies [1, 12]. For the pooled dataset, $M P D=92 \%$ (Fig. 4c).

The generalised regressions accounted for more than $98 \%$ of the variation in the values predicted by the original published equations, for total and stem biomass (Tab. V). The mean percentage difference between values obtained by generalised equations and those predicted by individual regressions for branch and foliage biomass was 58\% and 32\% respectively (Tab. V). Pastor et al. [21] reported similar per- centage difference values for branch mass, and assigned this large deviation to the difficulties in separating stem and branches in broadleaved trees. Differences in silvicultural treatments, or site productivity or stand age may also explain the obtained values.

In general, it is clear that inaccurate predictions may be obtained from generalised equations when applied to any particular stand. However, over- and under-estimations from generalised predictions may cancel out when these are applied to large geographical areas, but more data are needed to robustly test this hypothesis. This method might prove useful in estimating dry biomass values at a national level with minimum cost, since it appears to provide a good balance between accuracy of predictions and low input requirements. It is obvious that this method can also be applied for other tree variables or life forms.

\subsection{Comparison between equations}

The sustained total aboveground biomass per tree is greater for the study forest in Vermio mountain than for the Dutch or the Spanish forests, as implied by the coefficients of the allometric equations in Table II. Larger biomass values in Vermio mountain in comparison to the Dutch study may be explained by the fact that the wood density of beech trees growing in Greece is generally larger than for northern European beeches [18]. Alternatively, one could speculate that Greek trees support a larger biomass at any given $D$ in comparison to Dutch and Spanish trees. Surprisingly, American regressions more accurately predicted raw data for the Greek forest than Spanish or Dutch equations, contrary to speculation that trees growing in similar environment may sustain quite similar aboveground biomass. Stand structural characteristics or anatomical parameters of the study trees may also play an important role on biomass production and allocation.

Finally, the theoretical model [30] did not perform so accurately for the Spanish and the pooled dataset. Chambers et al. [5] who compared several models for trees growing in the tropical zone also reported the same conclusion. Thus, the applicability of this theoretical model at the stand scale is questioned and the use of constant $a$ and $b$ values for trees growing in different environmental conditions should be viewed as tentative; more work is required to test whether this theoretical model may be used at the landscape scale.

Acknowledgements: Christos Kontonasios and Thomas Zianis significantly contributed in collecting raw data. Dimitris Zianis is supported by Scholarship State Foundation of Greece (IKY) and Maurizio Mencuccini was supported by the EU-FUNDED CARBOAGE project (contract n. EVK2-CT-1999-00045).

\section{REFERENCES}

[1] Bartelink H.H., Allometric relationships for biomass and leaf area of beech (Fagus sylvatica L.), Ann. Sci. For. 54 (1997) 39-50.

[2] Baskerville G.L., Use of logarithmic regression in the estimation of plant biomass, Can. J. For. Res. 2 (1972) 49-53.

[3] Beauchamp J.J, Olson J.S., Corrections for bias in regression estimates after logarithmic transformation, Ecol. 54 (1973) 1403-1407. 
[4] Cannell M.G.R., World forest biomass and primary production data, Academic Press, London, 1982.

[5] Chambers J.Q., Santos J., Ribeiro R.J., Higuchi N., Tree damage, allometric relationships, and above-ground net primary production in central Amazon forest, For. Ecol. Manage. 5348 (2000) 1-12.

[6] Dafis S., Standortskundliche Untersuchungen in Buchenwaldern, Epist. Epet. Geopon. Dasol. Shol. Panepist. Thessaloniki 13 (1969) 1-48 (in Greek).

[7] Finney D.J., On the distibution of a variate whose logarithm is normally distributed, J. R. Stat. Soc. Series B 7 (1941) 155-161.

[8] Karagiannakidou V., Site research in beech forests of the Chortiatis mountain Range, NE Greece, Bot. Helv. 103 (1993) 23-27.

[9] Ketterings Q.M., Coe R., van Noordwijk M., Ambagau Y., Palm C.A., Reducing uncertainty in the use of allometric biomass equations for predicting above-ground tree biomass in mixed secondary forests, For. Ecol. Manage. 146 (2001) 199-209.

[10] Madgwick H.A.I., Biomass and productivity models of forest canopies, in: Reichle D.E. (Ed.), Ecological studies. 1. Analysis of temperate forest ecosystems, Springer-Verlag, New York, 1970, pp. 47-54.

[11] Madgwick H.A.I., Satoo T., On estimating the aboveground weights of tree stands, Ecol. 56 (1975) 1446-1450.

[12] McMahon T.A., Kronauer R.E., Tree structure: Deducing the principle of mechanical design, J.Theor. Biol. 59 (1976) 443-466.

[13] McWilliam A.L.C., Roberts J.M., Cabral O.M.R, Leitao M.V.B.R., DeCosta A.C.L., Maitelli G.T., Zamparoni, C.A.G.P., Leaf-area index and aboveground biomass of terra-firme rain-forest and adjacent clearings in Amazonia, Func. Ecol. 7 (1993) 310-317.

[14] Meadows J.S., Hodges J.D., Sapwood area as an estimator of leaf area and foliar weight in cherrybark oak and green ash, For. Sci. 48 (2002) 69-76

[15] Mountford M.D., Bunce R.G.H., Regression sampling with allometrically related variables with particular reference to production studies, Forestry 46 (1973) 203-212.

[16] Nihlgard B., Plant biomass, primary production and distribution of chemical elements in a beech and planted spruce forest in South Sweden, Oikos 23 (1972) 69-81.

[17] Niklas K.J., Plant allometry. The scaling of form and process, The Univ. Chicago Press, Chicago, 1994.

[18] Paraskevopoulou A., Physical and anatomical properties of beech (Fagus sp.) wood, For. Res. XI (1990) 45-79 (in Greek with English summary).

[19] Parde J., Forest biomass, For. Abstr. Rev. Art. 41 (1980) 343-362.
[20] Parresol B.R., Assessing tree and stand biomass: A review with examples and critical comparisons, For. Sci. 45 (1999) 573-593.

[21] Pastor J., Aber J.D., Melillo J.M., Biomass prediction using generalised allometric regressions for some Northeast tree species, For. Ecol. Manage. 7 (1984) 265-274.

[22] Payandeh B., Choosing regression models for biomass prediction equations, For. Chron. 57 (1981) 229-232.

[23] Santa Regina I., Tarazona T., Organic matter and nitrogen dynamics in a mature forest of common beech in the Sierra de la Demanda, Spain, Ann. For. Sci. 58 (2001) 301-314.

[24] Sfikas G., Trees and shrubs of Greece, Efstadiadis Group, Athens, 1978 .

[25] Shinozaki K.K., Yoda K., Hozumi L., Kira T., A quantitative analysis of plant form - the pipe model theory. I. Basic analysis, Jap. J. Ecol. 14 (1964) 97-105.

[26] Sprugel D.G., Correcting for bias in log-transformed allometric equations, Ecology 64 (1983) 209-210.

[27] Stefanidis G., Management plan of Naousa's forest, Municipality of Naousa, 1991.

[28] Strid A., Tan K., Mountain flora of Greece, Vol. 2, Edinburgh University Press, 1991

[29] Ter-Mikaelian M.T., Korzukhin M.D., Biomass equations for sixty-five North American tree species, For. Ecol. Manage. 97 (1997) $1-24$.

[30] West G.B., Brown J.H., Enquist B.J., A general model for the structure and allometry of plant vascular system, Nature 400 (1999) 664-667.

[31] Whittaker R.H., Bormann F.H., Likens G.E., Siccana T.G., The Hubbard Brook ecosystems study: forest biomass and production, Ecol. Monogr. 44 (1974) 233-254.

[32] Wiant H.V.J., Harner E.J., Percent bias and standard error in logarithmic regression, For. Sci. 25 (1979) 167-168.

[33] Yandle D.O., Wiant H.V., Estimation of plant biomass based on the allometric equation, Can. J. For. Res. 11 (1981) 833-834.

[34] Zar J.H., Calculation and miscalculation of the allometric equation as a model in biological data, Bioscience 18 (1968) 1118-1120.

[35] Zianis D., Mencuccini M., Allometric equations for beech trees (Fagus moesiaca Cz.) and biomass estimation along an elevation gradient in Vermio Mountain, northern Greece, in: Radoglou K. (Ed.), Proceedings of the International Conference: Forest Research: A Challenge For an Integrated European Approach, NAGREF, Thessaloniki, 2001, pp. 54-59. 